\title{
The first example of a highly non-symmetric ozonolysis of a sugar derived norbornene system
}

\author{
Sebastián A. Testero ${ }^{\mathrm{a}}$, Rolando A. Spanevello ${ }^{\mathrm{a} *}$, and Rakesh Kohli ${ }^{\mathrm{b}}$ \\ ${ }^{a}$ Instituto de Química Orgánica de Síntesis, Facultad de Ciencias Bioquímicas y Farmacéuticas, \\ Universidad Nacional de Rosario - CONICET, Suipacha 531, S2002LRK Rosario, Argentina \\ ${ }^{b}$ Mass Spectrometry Facility, Department of Chemistry, University of Pennsylvania, \\ 231 South $34^{\text {th }}$ Street, Philadelphia, PA 19104 \\ E-mail: rspaneve@fbioyf.unr.edu.ar
}

\section{Dedicated to Professor Edmundo A. Rúveda on his $70^{\text {th }}$ anniversary and to Professor Roberto A. Rossi on his $60^{\text {th }}$ anniversary}

(received 31 Jul 03; accepted 09 Sep 03; published on the web 24 Sep 03)

\begin{abstract}
The completely regioselective fragmentation of the primary ozonide formed during the ozonolysis of an unsymmetrical substituted norbornene system in the presence of methanol appears to be controlled by remote substituents and affords a tetrasubstituted cyclopentane moiety as a unique product in an almost quantitative yield.
\end{abstract}

Keywords: Unsymmetrical ozonolysis, Diels-Alder, norbornene, substituted cycloalkene, polysubstituted cyclopentane

\section{Introduction}

Ozonolysis is a widely applied reaction in organic synthesis. It is used to cleave multiple carboncarbon or carbon-hetero-atom bonds. Extensive investigation of the mechanism of alkene ozonolysis has confirmed the pathway originally proposed by Criegee. ${ }^{1}$ This process could be particularly interesting when an alkene is placed within a cyclic or polycyclic molecular structure. In this case the process could unveil a very useful functional group arrangement. A drawback that one could foresee is the generation of two similar functional groups, for example the ozonolysis of a cycloalkene would afford a dialdehyde or a diol upon treatment of the ozonide with methyl sulfide or sodium borohydride, respectively. From a synthetic point of view, the coexistence of two similar groups in a molecule could generate a serious problem for the subsequent regioselective manipulation of each of them. For this reason the possibility of 
providing two different functional groups through the ozonolysis of a cycloalkene in a regioselective manner is quite important.

\section{Results and Discussion}

The mechanism of the ozonolysis reaction proposed by Criegee consists of three steps: i) a [3+2] cycloaddition reaction of ozone with the alkene leading to formation of a primary ozonide (1,2,3trioxolane), ii) a cycloreversion process to provide the transient carbonyl oxide and a stable carbonyl compound, which may proceed in two different ways in the case of unsymmetrically substituted alkenes, iii) recombination of the carbonyl oxide and the carbonyl compound gives the 1,2,4-trioxolane.

It is well known the outcome of the ozonolysis of an olefin that has different number or type of substituents attached to the $\mathrm{sp}^{2}$ carbons. ${ }^{2}$ One could also anticipate the chemoselectivity of the ozone attack to a molecule with more than one double bond based on the balance between the electronic richness and steric hindrance, ${ }^{3}$ but it is not clear yet, which are the remote factors in a substituted cycloalkene that influence the regioselectivity during the cleavage of the primary ozonide in the presence of an alcohol. This procedure affords an aldehyde at one termini and a $\alpha$ alkoxy hydroperoxide at the other one, which upon the appropriate work up yields the corresponding ester (Scheme 1).

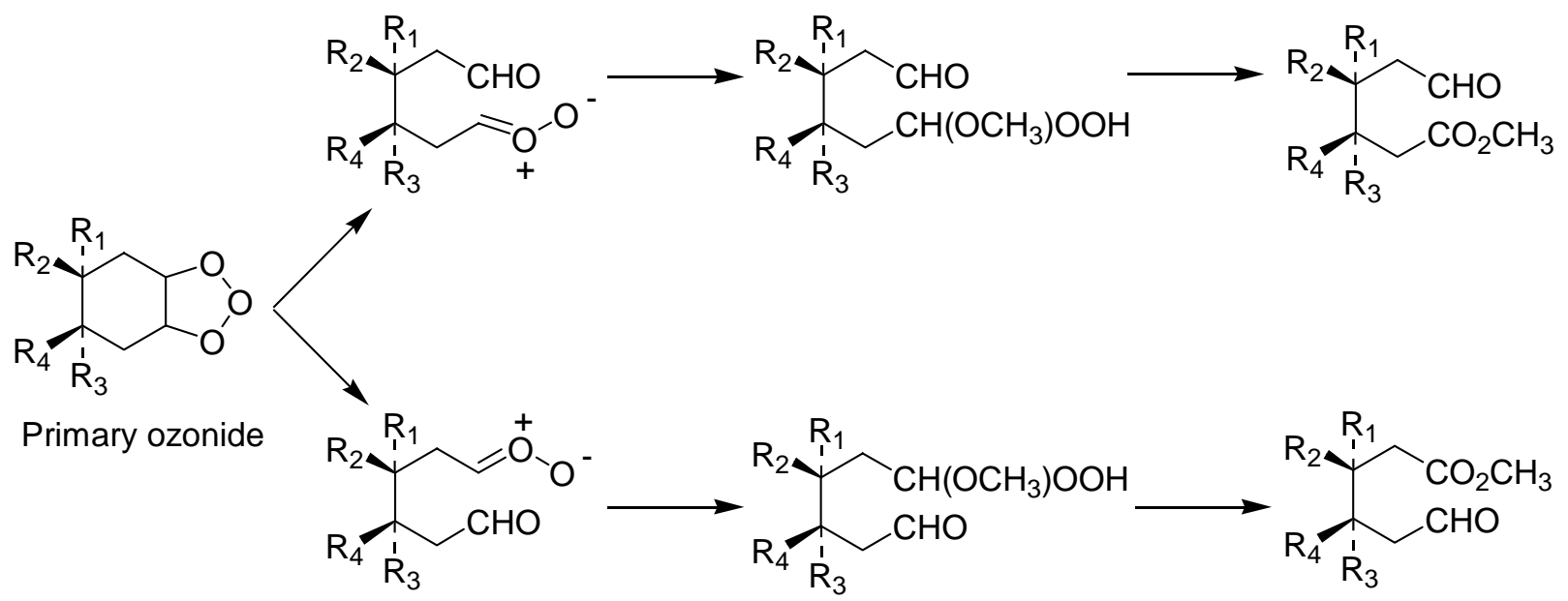

\section{Scheme 1}

Since the first unsymmetrical ozonolysis reported by Schreiber et al. ${ }^{4}$ in 1982 there were a few examples reported in the literature with moderate regiocontrol and yielding in all cases variable mixtures of compounds. ${ }^{5}$ This process could find a wide variety of applications in organic synthesis if it could afford only one regioisomer instead of a mixture of the two possible ones. Unsymmetrically substituted cyclohexenes are excellent substrates for this type of 
transformation and from a retrosynthetic point of view; a [4+2] cycloaddition reaction is the first choice for their preparation.

The Diels-Alder reaction is one of the most efficient methods for the stereoselective formation of carbon-carbon bonds through the construction of carbocyclic structures. When using a cyclic diene or dienophile, the outcome is a polycyclic system and if the dienophilic olefin is a tri or tetrasubstituted double bond it generates stereodefined quaternary centers.

The sequential combination of these apparently opposed processes, carbon-carbon bond forming and bond breaking, could uncover highly functionalized molecular structures (Scheme 2) paving the way to the synthesis of a wide variety of natural products possessing intricate carbocyclic skeletons.

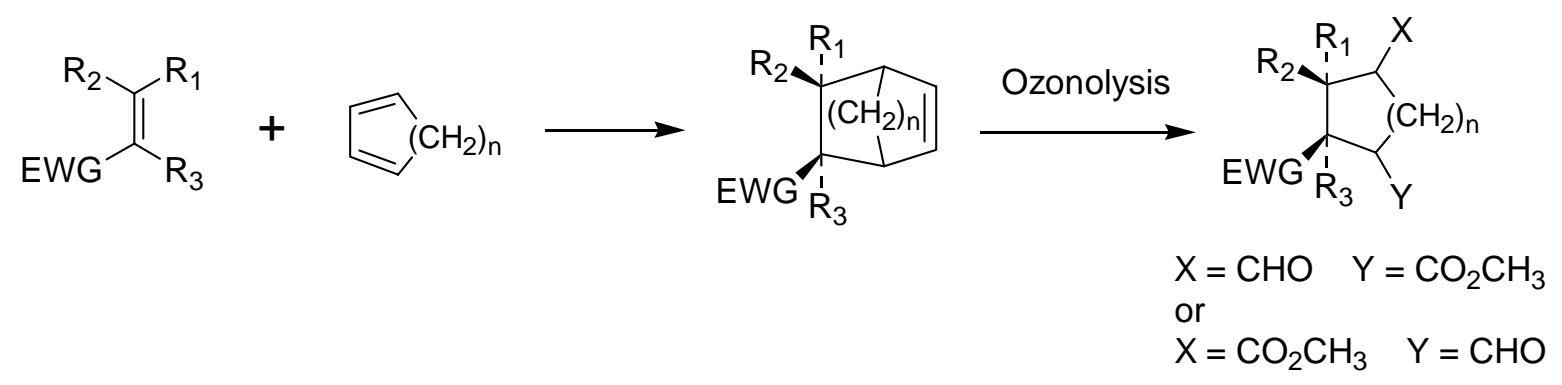

\section{Scheme 2}

We have previously reported the synthesis of enantiomerically pure cyclic dienophiles derived from glucose ${ }^{6}$ and studied the factors affecting the reactivity and diastereoselectivity of the Diels- Alder reaction of these dienophiles with cyclopentadiene. In this context, we found that the aldehyde $\mathbf{1}$ (Scheme 3) showed and exceptional exo and face selectivity affording the adduct 2 as a single product. ${ }^{7}$

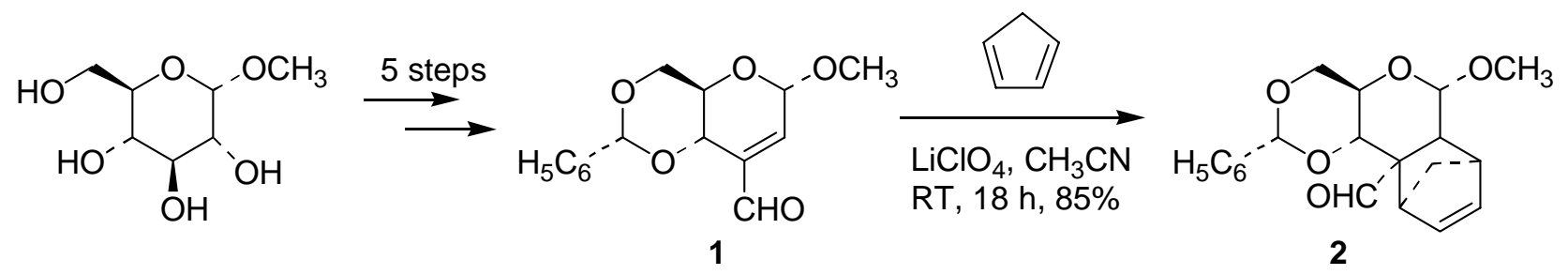

\section{Scheme 3}

Herein we wish to report the non symmetric ozonolysis of this carbohydrate derived norbornene system (2), that to the best of our knowledge is first example of a completely regioselective cleavage of the primary ozonide controlled by remote substituents, which after work up affords a polyfuntionalized cyclopentane in 92\% yield (Scheme 4). 
The ozonolysis of the cycloadduct 2 was carried out in a solution of dichloromethanemethanol with solid $\mathrm{NaHCO}_{3}$ in suspension. The crude reaction mixture was then treated with acetic anhydride and triethylamine in dichloromethane, to afford a tetrasubstituted cyclopentane moiety bearing two aldehyde groups (one from the original starting material attached at the quaternary center and the newly formed one) and a methyl ester.

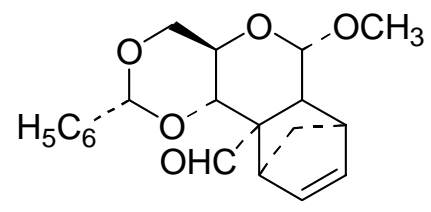

2

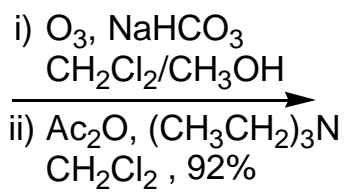

$\mathrm{CH}_{2} \mathrm{Cl}_{2}, 92 \%$

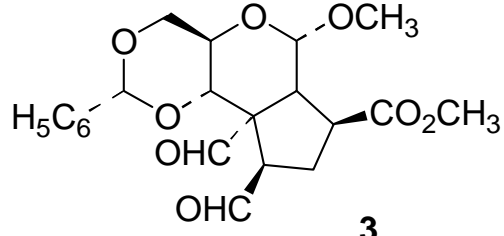

3

\section{Scheme 4}

As it was verified by the ${ }^{1} \mathrm{H}$ NMR spectrum of the crude reaction mixture, there was only one product formed and the reaction was exceptionally clean. The structure determination of compound 3 was based on spectroscopic evidences. The ${ }^{1} \mathrm{H}$ and ${ }^{13} \mathrm{C}$ NMR signals were assigned by using homo and heteronuclear 2D NMR techniques and NOE experiments. The proton spectrum showed two singlets at 10.22 and 9.65 ppm that were assigned to C-1-CHO and C-13CHO respectively based on the NOE effect observed between $\mathrm{H}-10$ and the aldehyde proton at lower field (Figure 1 shows atoms numbering). The absence of coupling constant between the proton of the newly formed aldehyde and its vicinal proton made more difficult to discern between the two possible regioisomer that could be formed. A singlet at $5.47 \mathrm{ppm}$ was assigned to the benzylic proton (H-4) and another singlet at $4.90 \mathrm{ppm}$ to the anomeric proton (H-9); other distinctive peaks were assigned as follow: a doublet at 4.08 to H-2, two sharp singlets at 3.72 and $3.39 \mathrm{ppm}$ to the methyl ester and the anomeric methoxy group respectively, a multiplet signal between 3.65-3.41 ppm to H-13, a two protons multiplet peak between 3.35-2.96 to H-12a and $\mathrm{H}-11$, and doublet at $2.70 \mathrm{ppm}$ to $\mathrm{H}-10$.

The NOE observed between the aldehyde proton attached at the quaternary carbon (10.22 ppm) and the $\mathrm{H}-13$ demonstrated that the substituent attached at $\mathrm{C}-13$ pointed towards the $\beta$-face and therefore $\mathrm{C}-13$ did not suffer any epimerization process during the treatment with triethylamine. Finally, determination of the regioselectivity of the non symmetric ozonolysis was achieved by a $\mathrm{C}-\mathrm{H}$ correlation via long range coupling (COLOC) ${ }^{8}$ that clearly showed a cross peak between the $\mathrm{H}-10$ and C-carboxylic, the cross peaks between $\mathrm{C}-11$ and $\mathrm{H}-10\left(\mathrm{~J}_{2}\right)$ and between $\mathrm{C}-13$ and $\mathrm{H}-2\left(\mathrm{~J}_{3}\right)$ added further support to the assignment. The ${ }^{13} \mathrm{C}$ data is summarized in Table 1. 


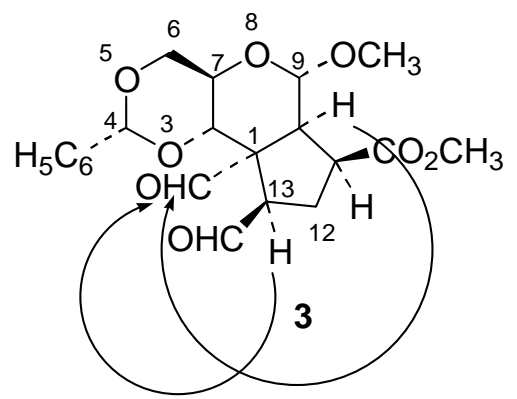

Figure 1. NOE data and atoms numbering.

Table 1. ${ }^{13} \mathrm{C}$ NMR chemical shift of $3(\mathrm{ppm})$

\begin{tabular}{|c|c|c|c|c|c|c|c|}
\hline C-1 & 58.8 & C-9 & 96.8 & C-1-CHO & 200.8 & C-ipso & 136.7 \\
\hline C-2 & 73.9 & C-10 & 52.8 & C-13-СНО & 198.6 & C-ortho & 128.1 \\
\hline C-4 & 102.0 & C-11 & 41.6 & $\mathrm{CO}_{2} \mathrm{CH}_{3}$ & 173.9 & C-meta & 125.7 \\
\hline C-6 & 69.2 & C-12 & 23.6 & $\mathrm{CO}_{2} \underline{\mathrm{CH}} \mathrm{H}_{3}$ & 52.3 & C-para & 128.9 \\
\hline C-7 & 59.8 & C-13 & 56.2 & $\mathrm{C}-9-\mathrm{OCH}_{3}$ & 55.0 & & \\
\hline
\end{tabular}

This highly non symmetric process is evidently controlled by substituents that are at least a distance of 2 carbons from the double bond. A noteworthy observation is the fact that the carbonyl group attached at the quaternary center is in an exo position with respect to the olefin in this norbornene system, therefore, we could discard it as the factor that control the cleavage of the primary ozonide through the space as in the case reported by Wu and coworkers. ${ }^{9}$

Comparison of Wu's norbornene system (4) with ours (Figure 2) allows us to assume that at least in our example the carbonyl group does not have a favorable spatial arrangement to induce the ozonide fragmentation. Hence, there must be other remote factors that control the outcome of the reaction. Further investigations are under way in order to determine the factors that may control the regioselective cleavage of the primary ozonide and will be published in due course.

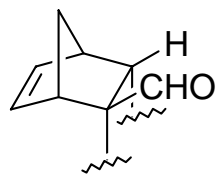

2<smiles>[R]OC1C2C=CC(C2)C1O</smiles>

4

Figure 2 


\section{Conclusions}

This is the first example of a highly non symmetric ozonolysis of an unsymmetrical substituted nonbornene system controlled by remote substituents that affords different functional groups at each termini. This strategy could become a very attractive synthetic approach for the synthesis of polysubstituted carbocyles.

\section{Experimental Section}

General Procedures. Optical rotation was recorded in a Jasco DIP 1000 polarimeter. The infrared (IR) spectra were determined as neat oils in a Bruker IFS 25 spectrometer. Nuclear magnetic resonance spectra were recorded on a Bruker AC-200 spectrometer with tetramethylsilane $=0.00$ as internal standard and deuteriochloroform $\left(\mathrm{CDCl}_{3}\right)$ as solvent. The HRMS was recorded on a Micromass Autospec using ESI as ionization technique. All reactions were monitored by thin layer chromatography (TLC) carried out on $0.25 \mathrm{~mm}$ E. Merck silica gel plates $\left(60 \mathrm{~F}_{254}\right)$ using UV light and anisaldehyde-sulfuric acid-acetic acid as developing agent. Flash column chromatography using Merck silica gel $60 \mathrm{H}$, was performed by gradient elution created by mixtures of hexanes and increasing amount of ethyl acetate. Dichloromethane was distilled from calcium hydride under dry nitrogen. Methanol was distilled from clean dry magnesium turning and iodine. All reaction mixtures were stirred magnetically, unless otherwise noted

Methyl 4,6-O-benzylidene-2,3-dideoxy-3-C-formyl- $\alpha$-D-erythro-hex-2-enopyranoside (1). It was prepared according to the procedure described in reference 6 .

$(1 S, 2 S, 3 S, 5 R, 8 R, 10 S, 11 S, 12 R)$ 10-methoxy-5-phenyl-4,6,9-trioxatetracyclo [10.2.1.0 $0^{2,11}, 0^{3,8}$ ]pentadec-13-ene-2-carbaldehyde (2). It was prepared according to the procedure described in reference 7 .

$(1 S, 2 S, 4 R, 7 R, 9 S, 10 S, 11 S, 13 R)$ 11, 13-Dicarbaldehyde-9-methoxy-4-phenyl-3,5,8trioxatricyclo [8.3.0.0 ${ }^{2,7}$ ]tridecane-11-carboxylic acid methyl ester (3). The aldehyde (2) (880.5 mg, $2.57 \mathrm{mmol}$ ) was dissolved in a 5:1 mixture of $\mathrm{CH}_{2} \mathrm{Cl}_{2}: \mathrm{MeOH}(5 \mathrm{ml})$ and solid $\mathrm{NaHCO}_{3}\left(865 \mathrm{mg}, 10.3 \mathrm{mmol}\right.$ ) was added. The suspension was cooled to $-78{ }^{\circ} \mathrm{C}$ and an ozone stream was bubbled through the suspension as it was stirred. Ozone addition was stopped when complete consumption of (2) was observed by TLC analysis. The mixture was then flushed with argon, and $\mathrm{NaHCO}_{3}$ was removed by filtration. The filtrate was concentrated in vacuo to give the crude as colorless oil, which was taken up in $\mathrm{CH}_{2} \mathrm{Cl}_{2}(12.8 \mathrm{ml})$. The mixture was cooled to $0{ }^{\circ} \mathrm{C}$, and acetic anhydride $(1.21 \mathrm{ml}, 12.85 \mathrm{mmol})$ and triethylamine $(537.3 \mathrm{ml}, 3.08 \mathrm{mmol})$ were added. The mixture was stirred at room temperature for $1 \mathrm{~h}$ and then partitioned between diethyl ether and, sequentially, $0.5 \mathrm{M}$ aqueous $\mathrm{HCl}, 0.625 \mathrm{M}$ aqueous $\mathrm{KOH}$, and brine. The combined organic extract was dried $\left(\mathrm{Na}_{2} \mathrm{SO}_{4}\right)$ and concentrated in vacuo. Chromatography of the crude 
product afforded $960.5 \mathrm{mg}(92.3 \%)$ of product as a colorless oil, TLC $R f(60 \%$ hexanes-40\% ethyl acetate $)=0.40$. HRMS (CI):calcd for $\mathrm{C}_{21} \mathrm{H}_{24} \mathrm{O}_{8}\left(\mathrm{M}+\mathrm{Na}^{+}\right)$427.13688. Found $\left(\mathrm{M}+\mathrm{Na}^{+}\right)$ 427.13585. $[\alpha]_{\mathrm{D}}-20.35$ (c=1.13, $\mathrm{CHCl}_{3}$ ); IR ( $\left.\mathrm{NaCl}\right) v_{\max }=2926$, 2864, 1724(broad), 1452, 1438, 1372, 1212, 1174, 1130, 1086, 962, $758 \mathrm{~cm}^{-1} ;{ }^{1} \mathrm{H}$ NMR $\delta=10.22$ (s, 1H, C-1-CHO); 9.65 (s, $1 \mathrm{H}$, C-13-CHO); 7.37-7.31 (m, 5H, aromatics); 5.47 (s, 1H, H-4); 4.90 (s, 1H, H-9); 4.33-4.21 (m, 2H, H-6eq, H-7); 4.08 (d, 1H, J=9.7 Hz, H-2); 3.72 (s, 3H, $\mathrm{CO}_{2} \mathrm{C}_{3}$ ); 3.75-3.66 (m, 1H, H-6ax); 3.65-3.41 (m, 1H, H-13); 3.39 (s, 3H, C-9-OC年3); 3.35-2.96 (m, 2H, H-11, H-12a); 2.70 (d, 1H, $\mathrm{J}=11.4 \mathrm{~Hz}, \mathrm{H}-10)$; 2.16-1.97 (m, 1H, H-12b).

\section{Acknowledgements}

This research was supported by the International Foundation for Science, Stockholm, Sweden and the Organization for the Prohibition of Chemical Weapons, The Hague, The Netherlands through a grant to RAS. SAT thanks CONICET for the award of a fellowship. Thanks are also due to Prof. M. González Sierra for his assistance with the NMR spectra and Mr. A. Poeylaut for his collaboration through the Undergraduate Research Program.

\section{References}

1. (a) Criegee, R.; Wenner, G. Ann. 1949, 564, 9. (b) Criegee, R. Ann. 1953, 583, 1. (c) Criegee, R. Angew. Chem., Int. Ed. 1975, 11, 745.

2. (a) Kawamura, S.; Yamaroshi, H.; Nojima, M. J. Org. Chem. 1996, 61, 5953. (a) Kawamura, S.; Yamaroshi, H.; Masuyama, A.; Nojima, M. Tetrahedron 2002, 50, 891 and references therein cited.

3. Schlessinger, R.H; Parsons, W.; Quesada, M. L., J. Am. Chem. Soc. 1980, 102, 889.

4. Schreiber, S. L.; Claus, R. E.; Reagan, J. Tetrahedron Lett. 1982, 23, 3867.

5. Taber, P. F.; Nakajima, K. J. Org. Chem. 2001, 66, 2515 and references therein cited.

6. Spanevello, R. A.; Pellegrinet, S. C. Synthetic Commun. 1995, 25, 3663.

7. Pellegrinet, S. C.; Spanevello, R. A. Org. Lett. 2000, 2, 1073.

8. Kessler, H.; Griesinger, J.; Zarbock, H. R.; Loosli, J. J. Magn. Res. 1984, 57, 331.

9. Wu, H-J.; Lin, C-C. J. Org. Chem. 1996, 61, 38. 